\title{
The Planning and Study Strategy of the Academic Famous Teachers' Studios
}

\author{
Aihua Wang \\ Qingdao No. 16 High School \\ Qingdao City, Shandong Province, China \\ E-mail:wangaihua16@189.cn \\ Junjie Qi \\ Qingdao No. 27 High School \\ Qingdao City, Shandong Province, China
}

\author{
Zhixue Sun \\ Qingdao Academy of Education Science \\ Qingdao City, Shandong Province, China \\ Zengxin $\mathrm{Li}^{*}$ \\ Qingdao University \\ Qingdao City, Shandong Province, China \\ e-mail:lizx57@126.com
}

\begin{abstract}
How to overcome the problem of loose organization, lack of initiative, lack of cooperation and low efficiency in the construction of the famous teacher's studio is an important issue to maintain the vitality of famous studios. "Aihua Wang studio" is the only junior high school famous chemistry teacher studio in Qingdao city. In the process of building two studios, through scientific planning, expert guidance, clear objectives, tasks and follow-up training evaluation measures, an excellent radiation leading platform will be built in Qingdao city. Some measures were taken such as focusing on key issues, forward-looking issues and actively undertaking projects. The teacher's studio has established functional modules such as "classroom polishing", "teacher guidance", "paper writing", "project research", and "online discussion". The studio members published more than 20 papers in professional core journals. The host was named "Top ten most beautiful teachers" in Qingdao. The members were awarded the first prize in the national high-quality class lecture class, the first prize in the national moral education lecture class, the second prize in the national experimental teaching lecture class and the first prize in the provincial moral education outstanding class. The Studio became an incubator for excellent personal growth of teachers.
\end{abstract}

Keywords-Junior high school; Chemistry; Famous teacher's studio; Teaching research

\section{INTRODUCTION}

In recent years, as a new mode of teacher training, a large number of famous teachers' studios have been built around the country. The purpose is to give full play to the leading teacher's demonstration radiation, so as to achieve the purpose of resource sharing, intellectual symbiosis and all staff promotion. According to statistics, about $50 \%$ of young teachers were under 40 years of age who have been teaching for more than 10 years among middle school chemistry teachers currently in Qingdao city Shandong Province. These teachers have a professional foundation and a certain amount of teaching experience. However, their research ability is poor. For example, only about $10 \%$ of the outstanding young professionals have been awarded the title of honor in Qingdao city, Shandong Province. The reason is due to their teaching experience which didn't been summarized and improved sufficiently such as writing peapers, essays and report items. There is an urgent need for an incubator base and academic platform to bring together outstanding teachers to become masters of the goal, personal growth as the direction of development, and to promote the growth and rapid growth of studio members through expert leading, joint discussions, and thought collisions. Since 2010, I have been honored as a super teacher in Shandong Province, paying attention to establishing a platform for cultivating and promoting the rapid growth of outstanding young teachers through the form of famous teachers' studios. In 2014, Qingdao City opened "Famous Teachers' Studios Project". Wang Aihua's Famous Teachers' Studios was successfully selected as a Qingdao City "Famous Teachers' Studios Project". According to the "Qingdao Famous Teachers' Studios Construction Program", members were selected strictly and the teachers' studio was composed of a host. It is composed of 8 members of the studio, including 4 members in the urban area of Qingdao and 4 members in the rural junior high school in the suburbs. In addition, a high school chemistry teacher is selected as a member to connect the junior high school. Teachers studio hosts and members are appointed by the Qingdao City Board of Education, the implementation of three-year term management. The studio takes the promotion of personal professional development as the development direction, carries out educational public welfare activities, helps rural areas or weak schools, and promotes the balanced development of urban and rural education. As a result of remarkable achievements, in 2007 the studio has been selected as 2nd batch of Qingdao City Famous Teachers' Studios. Summarizing the development process of famous studios and studios throughout the world, although some achievements have been made and some problems in development have also come into being, such as loosely organized and unscrupulous cooperation, insufficient cooperation and inefficiency, the crux of the problem lies in the 
unclear goal of work and high-end guidance Unclear, the task measures are not in place. Therefore, in order to avoiding the problem of loose organization and low efficiency during the development of the master teacher studio, the construction of the teacher studio focused on scientific planning, expert guidance, clear goals, task-based follow-up training, and evaluation. In order to build the characteristics and brand of the studio, the studio provides chemical teachers with a platform that has an influential role in Qingdao, and becomes a fastgrowing incubator for excellent teachers as the core task of the master studio [1].

\section{MAIN CONTENT OF STUDY}

\section{A. Focus on research and training, and strive to broaden their horizons}

In addition to actively participating in all kinds of training at all levels, members of the studio participated in " the Happy Class" led by American secondary education experts, hired academic experts from colleges and universities to make academic reports and constantly updated their educational concepts. Each member completed at least 3000 words of listening notes and study at least 4 times a year. In order to understanding the frontiers of chemistry research, the studio also carried out the activity of "Going into university laboratories", and successively visited the Fine Chemical Laboratory of Tianjin University, the Ocean Resources Laboratory of Ocean University of China, the Nutrition and Health Laboratory of Medical College of Qingdao University, feeling experience atmosphere of universities and the practical application of chemistry. The workshops often hold symposiums, where teachers from different regions exchanged ideas and explored new ways of teaching, sparking wisdom in the collision and debate of different thoughtpoints. The host is hired as master of education in Qingdao University mentor, assume the timing of teaching and mentoring master students, studio members are required to participate in the entire process of education master's training, including the opening report, the mid-term inspection and reply links, to enhance the level of theoretical research members [2-4].

\section{B. Sub-topics setting task based follow-up training}

The teacher's studio has set up function modules such as "Classroom Polishing", "Master Teacher Guide", "Paper Writing", "Project Research", and "Online Discussion". It conducts training activities and displays the research process through the Internet platform. These activities are open to middle school teachers in the city. Among them, the "lesson sanding" activities are hold at least twice in a semester, showing studio preparation, class, research process, the teaching site and teaching process repea tedly presented; "teacher teacher" activities per unit, at least every semester Complete the two units of "teacher-teacher education" activities, combined with hot issues, organizing online seminars; "Paper Writing" activities first expert consultants do thesis writing skills lectures, and guide members to observe the excellent teaching video, teaching record start . Create at least 2 "hard-fought" lessons per semester and record the images; follow these 3 steps.
(1) Convert famous teacher's lesson video into classroom literary record so as to restore the famous teacher's classroom and tap the wisdom of the famous teacher. By analyzing the master's lesson record, the teacher's sense of wisdom can be enhanced. At the same time, a different perspective threedimensional comprehensive analysis and interpretation are so more accessible, easy to find members to learn and use for reference.

(2) The studio host and expert consultant conduct at least one effective classroom diagnosis for each member of the studio, and use clip playback to analyze and comment on each one. Members converted their own public lectures that had been repeatedly polished into textual recordings. In the process of conversion, you can calm yourself down and consider carefully, have a clearer and more comprehensive understanding of your class, and analyze your strengths and weaknesses. Reflect on each other on the basis of classroom records and write postscripts in class.

(3) Analyze the teaching ideas, design intent, teaching methods, and highlights in the dialogue record in the classroom record. Grab one or two points and expand into a thesis. Each "paper writing" activities, layout papers homework, after review by the moderator to modify, the next activity to be commented. After several reincarnations, members learned how to choose the essay. The members reflected that the papers written in this way have practical examples that can be demonstrated and published [5].

\section{Members take turns hosting to ensure symbiotic growth}

The enthusiasm of studio members to participate is an important factor in the smooth running of the master studio. The vitality of the teacher's studio lies in the symbiotic growth of the studio's members. In order to mobilize the enthusiasm and creativity of the participants, the teacher's studios should have a common vision of mutual trust and cooperation among the participants. Participants must have a good subject literacy, a strong ability to study and a higher level of information technology [3]. Master studio teacher in charge of the overall studio operation and various activities, but the protagonist of each event is not host "dominate", each member of the studio can be the protagonist. Each event to the activities of the difficult to determine which member is responsible for determining from the theme, experts hired, informed, venue layout to host the seminar, write the report is responsible for the entire process, the host only to give guidance and assistance. Such activities, each member actively active, have been tempered and raised [6].

\section{Radiation guidance}

The famous teacher itself is a kind of high-quality educational resource. The teacher must demonstrate, lead, and radiate through the studio. Ms. Aihua Wang held lectures on public welfare in districts of Laoshan, Jimo, Huangdao and Laixi respectively. The host make a report to the high school chemistry teachers to do discipline literacy training in Qingdao and to the chemistry backbone teachers do discipline literacy training in the country. Wenwei Zhou held two lectures on public welfare and undertook the training and guidance of teachers in Shibei District; Junjie Qi, Wei Zhang, Wenwei 
Zhou and Yan Wan each held two teacher's lectures for public interest and Huirong Teng held a teacher's lecture on public interest. These lectures are very popular with students. Studio members Yan Wan, Qian Gao, Wei Zhang and Shuhong Sun each held an open class section. Hosts and members held 18 lectures on "Qingdao Famous Teachers Classroom". These lectures were opened by members of the teachers studio for junior high school students and parents in the city. Students register online, meet the program of third year of middle school, contact students' chemistry study, senior high school entrance examination review strategies and future professional planning and popular with students. The Studio released living information more than 20 articles by the city education and research network, sharing the teacher's studio experiences with whole teachers in the city. In the Qingdao high school chemistry joint teaching and research activities. The exhibition and lecture were held on " Teaching achievements showing of Aihua Wang teacher studio " .The host showed the series of studio results, in kind and pictures .One studio member showed the " Properties of acid " of the open class lecture. Another member made a speech title as "teacher led the boost growth"to more than 300 chemistry teachers to lead the demonstration.

Help and bring the schools were selected as No. 8 High School in Laoshan District and No. 4 High School in Laixi city. The memberes enter these schools many times to hold public lectures and to carry out teaching and research exchanges with all teachers of the schools, to provide teachers with reasonable advice and support for teachers' teaching and diagnosis; Participate in teaching competitions, participate in the precontest course of training, guide the teachers out of the advantages, find out the differences, find ways to improve together. Through the competition and the exchange of exhibition so that the teacher's teaching demonstration, the advanced nature of ideas can be reflected. Set goals and plans together with teachers in help-out schools to solve their weak points in the process of growth and development, and promote outstanding experience and achievements of the host and members through teacher-teaching demonstration classes, classroom diagnosis, and task-following guidance. Improving the educational and teaching standards of the helping and supporting schools. The host's open class in Qingdao was on the scene to help the school and the "acidity and alkalinity of the solution" presentation class introduced topics such as lemons, apples, household spirits, detergents, sprites, and soapy water, to lead students gradually into the life of chemistry. Leave time to students sufficient, let the students classify simply the solution on the table according to their own experience. After a simple study, they were verified the classification is correct. In the classroom, a variety of methods such as litmus test solution and leuco phenolphthalein test solution are also used to allow students to select and verify. In order to the improvement of effectiveness of classroom experiments, the teachers used different drugs for each group of students, so that different groups of students can learn how to test the acidity and alkalinity of the solution through different experiments. On the basis of this study, students will learn how to use the $\mathrm{pH}$ meter to further test the acidity and alkalinity of solutions in industry and in their daily life. At the same time, chemist Mr. Boyle discovered the discovery history of acid-base indicator to the students, inspired the students to seek scientific footprint, and usually cultivated the scientific literacy of observation and thinking. Through teamwork, we conducted a multi-faceted and multi-angle experiment to explore students 'various ways to successfully test the acidity and alkalinity of solutions and to develop students' ability to explore and cooperate with each other. Master Wang's ability to master the classroom and handle problems has left a deep impression on lecturers. Excellent on-site teaching activities during the demonstration, the advanced teaching concepts to help schools, but also for many long-term subjects in the classroom reform of many doubts and obstacles for an exemplary breakthrough. Qingdao Academy of Sciences Mr. Zhixue Sun made wonderful comments on this class and affirmed Wang's advanced teaching concepts and classroom driving ability. It points out that moral education is chemistry education. The member Wan Yan made a speech entitled "Master Teacher Leads Happiness Growth", and Mr. Kuiqiang Wan of Laoshan No. 8 made a speech of "Practicing a Classroom for Effective Classroom". At the same time, he had a discussion meeting with the rural support schools and the chemical teachers of the district where they live. Qingdao The master teacher studio led the studio members to present the books to Laoshan No.8 high school. Both of members teaching and the members' exchange speeches were highly praised by the school and the district's teachers and researchers. The studio also encouraged members to work in the studio. The learned, done, and gained results are passed on to the teachers' peers in their school, and they play their own role in promoting and radiating. For example, the rapid growth of Ms. Yan Wan a member of the studio, led to the enthusiasm of research for the other three chemistry teachers. He actively wrote papers, published 4 papers, and won city awards in guiding students' small thesis activities. The great response of the school has stimulated the enthusiasm for research in other disciplines. [7]

\section{E. Abundant resources to improve evaluation}

The resources (such as courseware, material, etc.) of the teacher studios need to be regularly supplemented, improved, and updated through social resources such as excellent academic websites. Studio members participate in the research of the project, constantly summing up the experience of studio construction, and also making each member become the carrier of knowledge management, thereby enriching, sharing, and using resources and accumulating knowledge value [4]. In order to ensure that the studio host and members perform their duties, the host's school provides an independent 30-squaremeter office for the master studio's activities, and is equipped with office conference tables, chairs, computers, network equipment, and some professional books [8].

\section{CONCLUS ION AND PROSPECT}

With the practice of junior high school chemistry master studio in Qingdao city for four years, the professional growth performances of the studio host and members are significant. The studio host presided over the participation of members in the Shandong Provincial Teaching Research Project "Analysis and control of teacher-student psychology problems in chemical inquiry experiment teaching under the new curriculum" and "The development and research of junior high 
school grade-shifted school-based curriculum". About 50 series of classic cases were edited by the host and members participated in the publication of monographs. More than 20 papers have been published on professional core journals such as "J. Chem. Edu.", "J. Teach. Refer. in Middle Schools Chem.." The host was named "Top Ten Most Beautiful Teachers" in Qingdao city. Special edition introduced deeds of the special teacher Ms. Aihua Wang in "J. Qingdao Edu." (2015, Issue 5). The teacher studio actively encouraged members of the studio to participate in various teaching competitions and appraisal activities. The members were awarded the first prize in the national high-quality class lecture class, the first prize in the national moral education lecture class, the second prize in the national experimental teaching lecture class, the first prize in the provincial moral education excellence class, the first prize in the Qingdao high quality class, the first prize in the micro class, and a division A gifted class award. The members have given lectures on the Qingdao News Broadcast "Educational New Observation" for many times; they have instructed the students to win three awards for the research study papers in Qingdao city; two awards have been awarded for the Qingdao Innovative Experiment Award; three have been awarded as teaching experts in Qingdao; Ms.Zhou was appraised as the district teacher studio host, One was awarded the district teaching expert; One was named the academic leader of Qingdao city; One was awarded the excellent class teacher of Qingdao city. Every studio member is the backbone of the education and teaching of each school, and they all undertake heavy tasks [9-10].

Looking back at the work in the past four years, there are still some regrets and deficiencies. The studio members are subject to the work requirements and geographical constraints of their respective schools, and it is difficult to have a unified time for systematic and continuous collective research and work. Most of the time, they rely on network communication, which makes communication between members. Lack of a certain degree of depth and breadth of cooperation, the crystallization of collective wisdom also faces greater obstacles. Wang Aihua Studio will continue to give full play to the characteristics of a teacher, focus on education and teaching practices, focus on the classroom, lead by a teacher, practice reflection, teamwork, public lectures to help weak schools, and actively explore scientific and efficient cultivation of outstanding personnel growth mechanism, in and outside the province of junior high school chemistry The teaching area has played a unique role in leading radiation.

\section{REFERENCES}

[1] Xuelin Li, Qin Tang. "Practice and exploration of academic teacherstraining". Educational Research \& Review, 2017(4). (In Chinese)

[2] Zhang Dan, Zurong Zhong "Practical Exploration of the Thematic Driven Cooperative Training Model for Backbone Teachers". Research on Education Science, 2012(12). (In Chinese)

[3] Li Ma. "Teacher professional growth in the teacher's studio environment Perspective of a professional community", Contem. Edu. Sci., v2009(13). (In Chinese)

[4] Guangsheng Ren, Wei Li. "Exploring the Operating Mechanism of Famous Teachers Studio",Contem. Edu.Sci., 2011(14). (In Chinese)

[5] Shijie Sun "Analysis on the Survival Status of Famous Teachers' Studios,Problem Countermeasures and Suggestions",Tianjin Edu., 2011(3). (In Chinese)

[6] Minglan Teng. 'From 'Collaborative Partnership' to 'Common Development': A Study on the Cooperation between Universities and Primary Middle Schools". Edu. Develop. Res., 2008 (22). (In Chinese)

[7] Lu Wang. "Argumentation of concept and characteristics of famous teacher".Tianjin Academy of Educational Science,2005(4). (In Chinese)

[8] Guanzhong E. "Discussion on the Operation Strategy of the Regional Master Studios". Elementary and secondary school teacher training, 2012(6). (In Chinese)

[9] Canhua He. "Teacher cooperation in the teacher studio". Shanghai Edu. Res., 2013 (12). (In Chinese)

[10] Jifei Hu. "Problems and Suggestions for the Construction of Teachers' Studios in Primary and Secondary Schools". Elementary Education, 2012(4). (In Chinese) 